\begin{tabular}{|c|c|}
\hline $\begin{array}{l}\text { European Association for the Development of Renewable } \\
\text { Energies, Environment and Power Quality (EA4EPQ) }\end{array}$ & $\begin{array}{c}\text { International Conference on Renewable Energies and Power } \\
\text { (ICREPQ'10) }\end{array}$ \\
Granada (Spain), 23rd to 25th March, 2010
\end{tabular}

\title{
Analysis of unstable phenomenon in TCSC by experiment and simulation
}

\author{
Hiroki Muramatsu and Junya Matsuki \\ University of Fukui \\ 3-9-1, Bunkyo, Fukui-city, Fukui, Japan \\ Phone/Fax number: +776-27-8930 \\ Fukui, Japan \\ e-mail: mucchan_84@yahoo.co.jp
}

\begin{abstract}
In this paper, we have investigated damping effect of power oscillation and unstable phenomena by TCSC (Thyristor Controlled Series Capacitor) which is one of FACTS (Flexible AC Transmission Systems) controller. In this paper, we changed the capacitance of capacitor in TCSC prototype from $146 \mu \mathrm{F}$ to $73 \mu \mathrm{F}$ to enhance the damping effect of power oscillation. But we found that the thyristor in TCSC could not work correctly under some operating conditions. It is called an unstable phenomenon of TCSC. So we have examined the unstable phenomenon by means of both experiment and simulation.

As a result, we conclude that reducing the capacitance of capacitor in TCSC is generally effective in damping oscillation, but we also found that it is necessary to grasp the region of stable operating conditions where the TCSC can operate normally.
\end{abstract}

\section{Keyword}

TCSC (Thyristor Controlled Series Capacitor)

Unstable phenomenon, Firing angle

Power oscillation damping

\section{Introduction}

Recently, the power electronic technology has been introduced in large scale electric power systems as FACTS controllers. Among FACTS controllers, TCSC is expected to control power flow and to improve power system stability.

In the past, we constructed a TCSC prototype connected to a laboratory scale power system, which consists of including a 6kVA synchronous generator, a $220 \mathrm{~V} / 3300 \mathrm{~V}$ step-up transformer, a $3300 \mathrm{~V} / 220 \mathrm{~V}$ step-down transformer and simulated transmission line. Using the laboratory system, we confirmed that TCSC has effective damping effect of power oscillation.

In this paper, we changed the capacitance of capacitor in TCSC from $146 \mu \mathrm{F}$ to $73 \mu \mathrm{F}$ to

enhance the damping effect of power oscillation. But we found that the thyristor in TCSC could not work correctly under some operating conditions. It is called an unstable phenomenon of TCSC. So we have examined the unstable phenomenon by means of both experiment and simulation. Capacitor voltages, thyristor currents and line currents were measured and calculated. These data were analyzed by FFT analysis.

\section{Outline of TCSC prototype and laboratory scale power system}

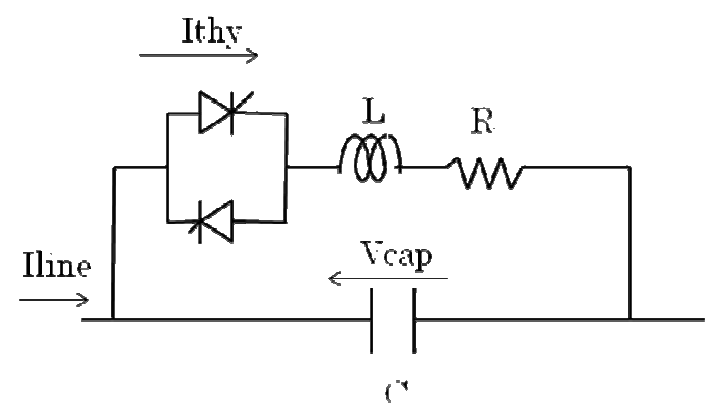

Fig.1. Configuration of TCSC prototype 


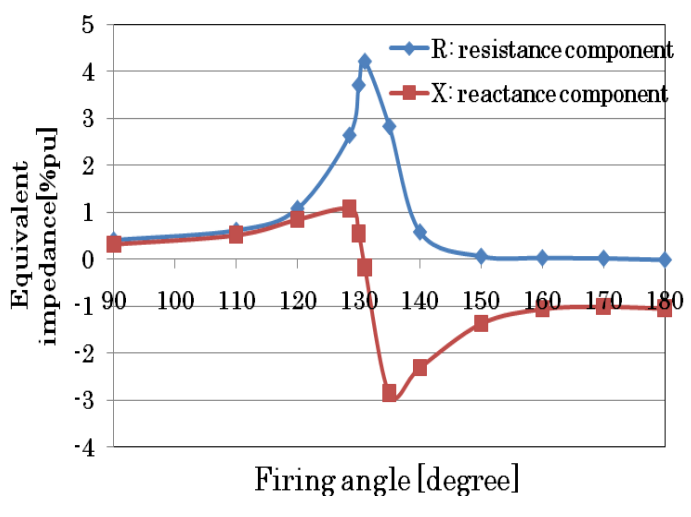

Fig.2. Experimental results of Impedance characteristic of TCSC

Configuration of TCSC prototype is shown in Figure.1. It consists of the series compensator capacitor shunted by a Thyristor Controlled Reactor. In experimental equipment, capacitance of the capacitor was designed so that the reactance component becomes $1 \%$ for the $6 \mathrm{kVA}$ synchronous generator and $3300 \mathrm{~V}$ transmission system. It is $146 \mu \mathrm{F}$. Two capacitors were made. Capacitance can be $292 \mu \mathrm{F}$ or $73 \mu \mathrm{F}$ by connecting the two in series or parallel. Inductance of the reactor is $10 \mathrm{mH}$ and resistance is $2 \Omega$. Ratings are $600 \mathrm{~V}$ for capacitor, $5 \mathrm{~A}$ for reactor and resistor, and $1600 \mathrm{~V}, 200 \mathrm{~A}$ for thyristors.

Impedance characteristic of TCSC is shown in Figure.2. The equivalent impedance can be changed continuously by changing the timing of conduction state of the thyristors.[1]

In this paper, TCSC is classified into the following five operating conditions.

Firing angle is $90^{\circ}$..."bypassed thyristor mode" Firing angle is $180^{\circ}$...blocked thyristor mode" The reactance component is in a positive range..."'inductive region",

The reactance component is in a negative range..."capacitive region" The reactance component is between maximum of inductive reactance and maximum of capacitive reactance..."resonance region"

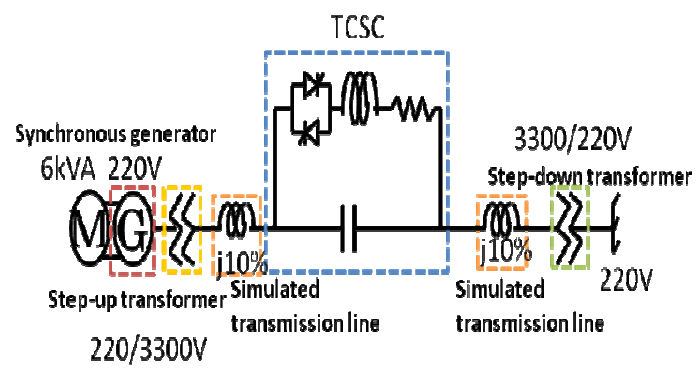

Fig.3. Single machine infinite bus system
Figure. 3 shows the single machine infinite bus system in the experiment. It consists of a $6 \mathrm{kVA}$ synchronous generator, a $220 \mathrm{~V} / 3300 \mathrm{~V}$ step-up transformer, a $3300 \mathrm{~V} / 220 \mathrm{~V}$ step-down transformer, $10 \% \mathrm{pu}$ simulated transmission line and the TCSC.

\section{Damping effect of Power oscillation}

Synchronous generator is kept stable in the rating 6kVA by using Figure.3. Then the three-phase short-circuit fault is occurred in front of TCSC.

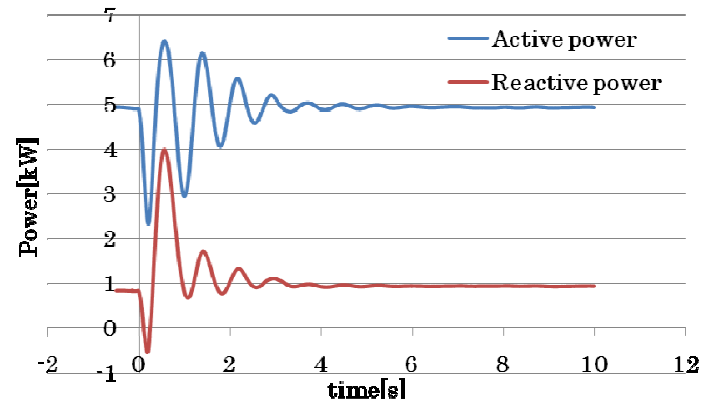

Fig.4 Power oscillation with TCSC

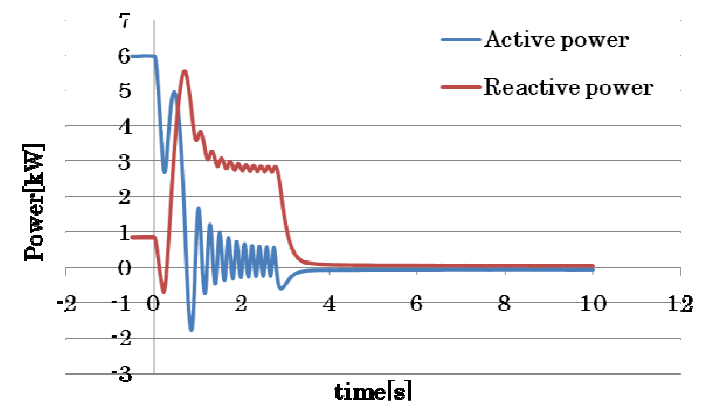

Fig.5 Power oscillation without TCSC

Figure.4 shows power oscillation for using Figure.3. Figure.5 shows power oscillation for using Figure. 3 without the TCSC.

As a result, the synchronous generator becomes loss of synchronism after fault in Figure.5. But power oscillation is able to be damped without loss of synchronism in Figure.4. Therefore, it is thought that TCSC has a damping effect of power oscillation. It can be also expected to enhance the stability by reducing line inductance. [2]

Here, capacitance of capacitor was changed from $146 \mu \mathrm{F}$ to $73 \mu \mathrm{F}$. The impedance characteristic of TCSC was shown in Figure.6. 


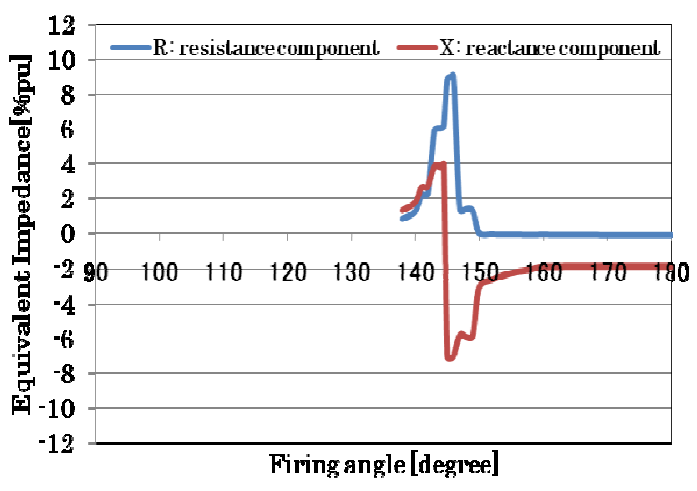

Fig.6 Impedance Characteristic by experiment

Compared to Figure. 2 which is the impedance characteristic of capacitance $146 \mu \mathrm{F}$, minimum value of reactance component in Figure. 6 is smaller than minimum value of reactance component in Figure.2. Therefore, capacitance $73 \mu \mathrm{F}$ decreases line inductance more than capacitance $146 \mu \mathrm{F}$. It is thought that reducing capacitance of capacitor is effective in power oscillation damping.

\section{Analysis of unstable phenomenon in TCSC}

Capacitance of capacitor in TCSC was changed from $146 \mu \mathrm{F}$ to $73 \mu \mathrm{F}$, and synchronous generator is kept stable in the rating 6kVA by using Figure.3. Capacitor voltage (Vcap), line current (Iline) and thyristor current (Ithy) were measured when changing the firing angles from $90^{\circ}$ to $180^{\circ}$.

As a result, we find that there is an area where TCSC becomes unstable. Therefore, we analyze the unstable phenomenon of TCSC. This analysis uses Matlab/simulink simulation, FFT and experimental results.

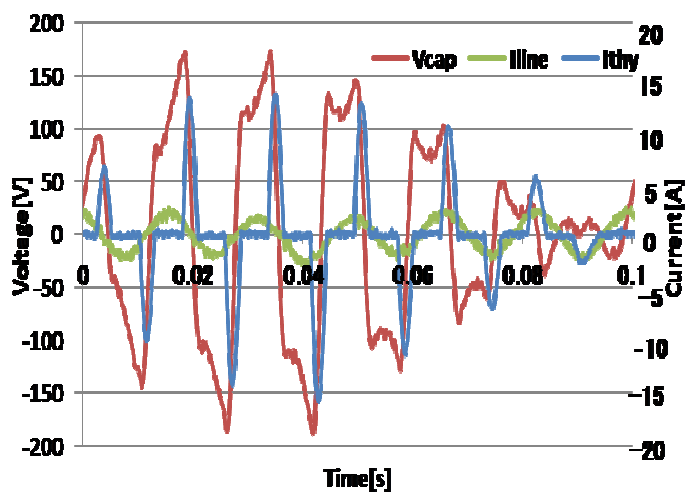

(a) Experimental waveshapes

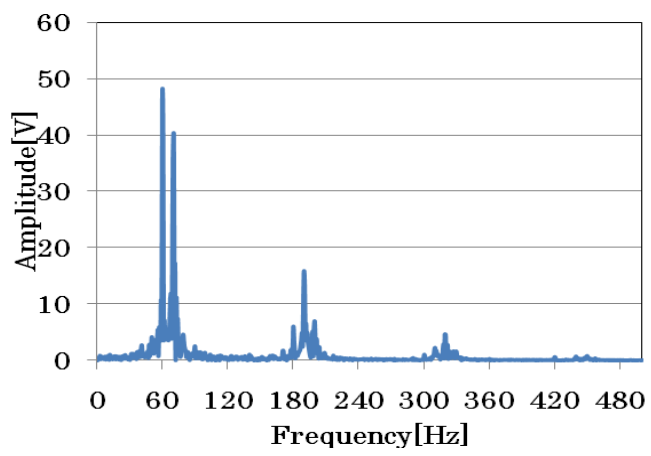

(b) Results of FFT analysis

Fig.7 Experimental results at firing angle $133^{\circ}$

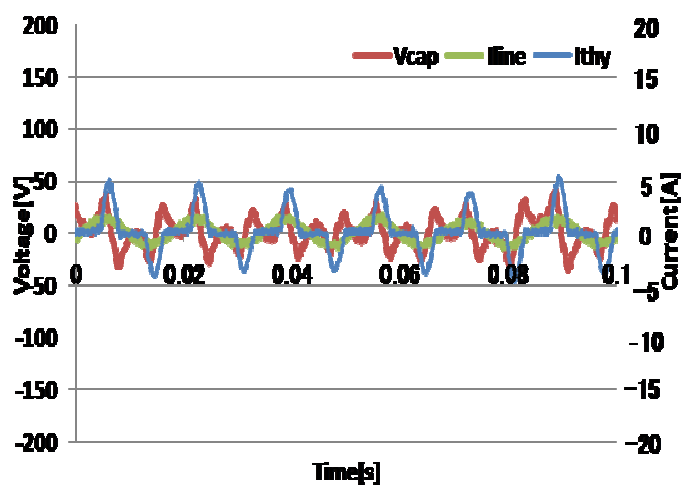

(a) Experimental waveshapes

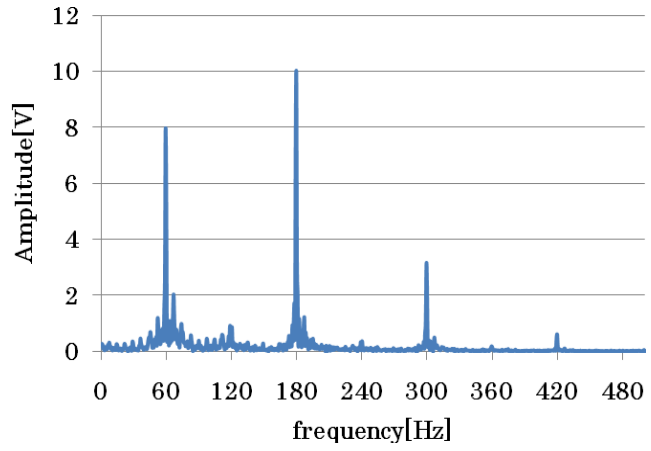

(b) Results of FFT analysis

Fig. 8 Experimental results at firing angle $137^{\circ}$

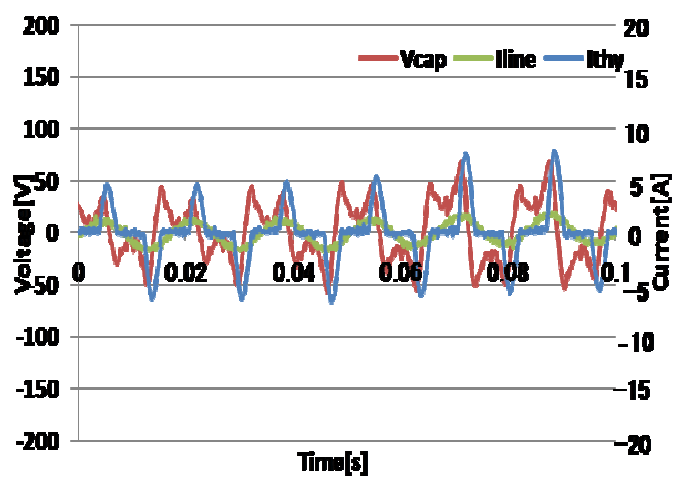

(a) Experimental waveshapes 


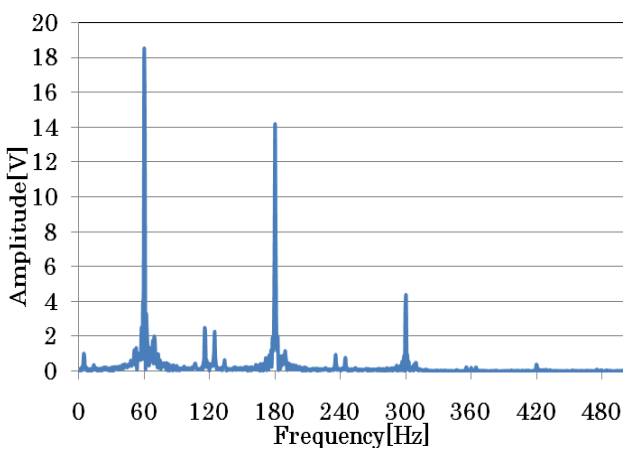

(b) Results of FFT analysis

Fig.9 Experimental results at firing angle $138^{\circ}$

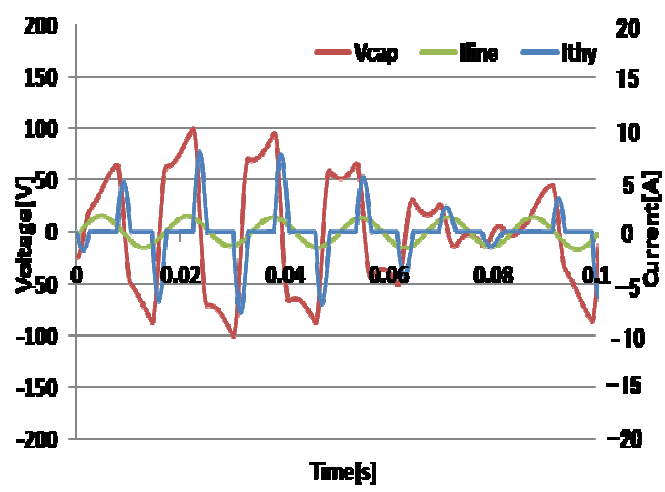

(a) Simulation waveshapes

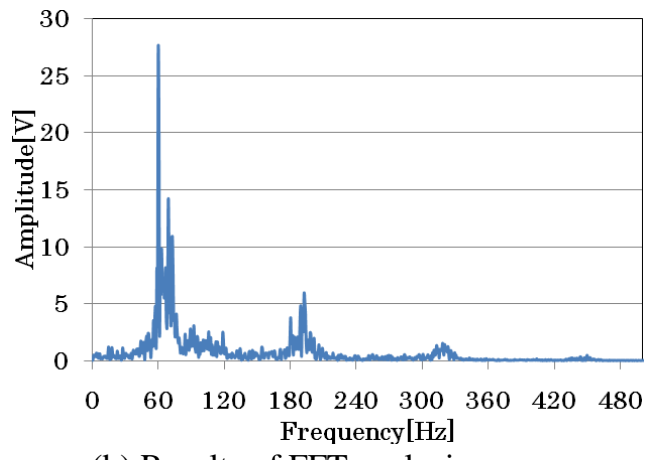

(b) Results of FFT analysis

Fig.10 Simulation results at firing angle $136^{\circ}$

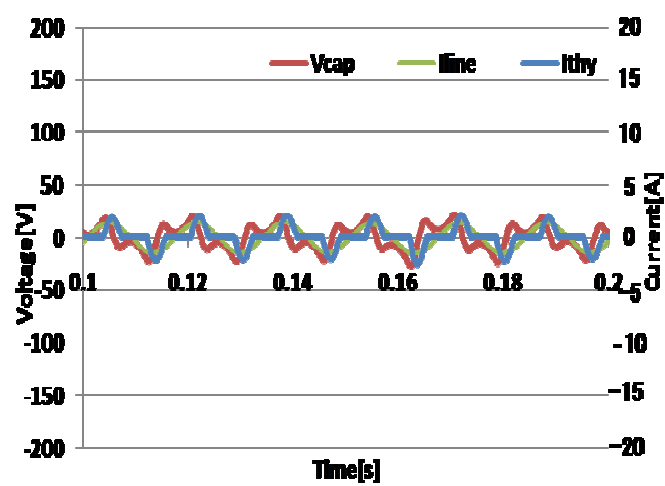

(a) Simulation waveshapes

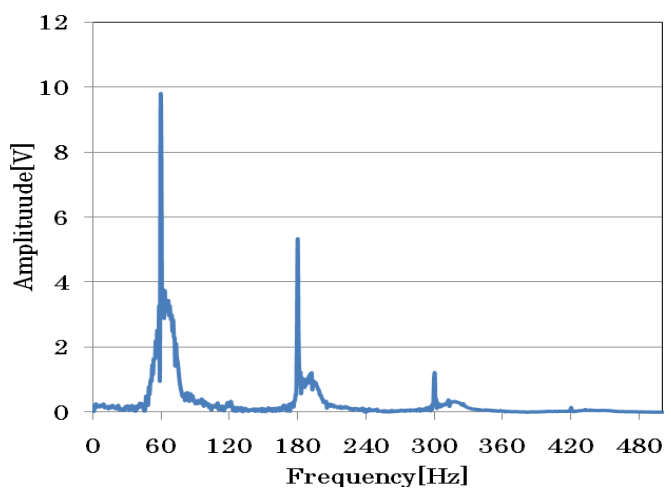

(b) Results of FFT analysis

Fig.11 Simulation results of firing angle $136^{\circ}$

Figure 7,8 and 9 show the experimental results of Vcap, Iline, and Ithy at $133^{\circ}$, $137^{\circ}$ and $138^{\circ}$, respectively. Capacitor voltages normally cross the zero axis every half cycle, but a new zero crossing within half cycle occurred around 0.08s as shown Figure.7(a). Therefore, the thyristor which are fired based on zero crossings of the capacitor voltages can't fire accurately. To verify this cause, we analyzed the capacitor voltage by $\mathrm{FFT}(\mathrm{Figure} .7(\mathrm{~b}))$. It is indicated that the cause is that $73 \mathrm{~Hz}$ and $192 \mathrm{~Hz}$ are strong besides basic frequency component, a third high harmonic and a fifth high harmonic. In the case of Figure.8, capacitor voltages have a new zero crossing within every half cycle. This phenomenon occurred from firing angle $134^{\circ}$ to $137^{\circ}$. As an analytical result from $134^{\circ}$ to $137^{\circ}$, the cause of this phenomenon is a third high harmonics component. In the case of Figure.9, only the basic frequency component, the third harmonis component and the fifth harmonis component exist. Then, TCSC operates normally. Figure.10 and Fig.11 show the simulation results. These meet largely with the experimental result.

Figure.12 shows the impedance characteristic of TCSC by simulation. We understand the range where the TCSC can be operated normally when the capacitance of capacitor is $73 \mu \mathrm{F}$ is narrowed compared with when the capacitance is $146 \mu \mathrm{F}$ as shown in Figure.2. 


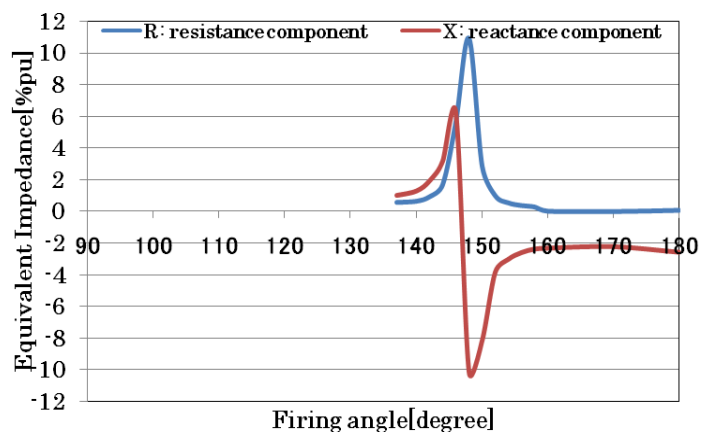

Fig.12 Impedance Characteristic by simulation

\section{5.further information}

*Graduate school of Electrical and Electronics Engineering, University of Fukui 3-9-1, Bunkyo, Fukui, 910-8507, Japan e-mail: mucchan_84@yahoo.co.jp

\section{Conclusion}

When Capacitance of capacitor in TCSC was changed $146 \mu \mathrm{F}$ to $73 \mu \mathrm{F}$, we analyze the unstable phenomenon in TCSC by experiment and simulation. The results confirmed that it was a cause that the thyristor can't fire accurately because the capacitor voltage caused a few zero crossings from the influence of the high harmonics in half cycle. To obtain a further damping effect of a power oscillation, it is necessary to reduce the capacitance of capacitor and to increase the equivalent impedance. But we understand that it is necessary to grasp the range where the TCSC can be operated normally.

\section{References}

(1)NARAIN G. HINGORANI and LAZLO GYUGYI

$\lceil$ Understanding FACTS 」, WILEY-INTERSCIENCE, A JOHN WILEY \& SONS, INC, PUBLICATION 2000

(2)JUNYA MATSUKI, YASUHIRO HAYASHI, YOSHIYUKI SAITO and LANG HONG

$\lceil$ Improvement of power system stability by TCSC $\rfloor$, International Conference on Electrical Engineering 2007, HONG KONG 